the aetion of quinine in scarlatinal dropsy is most productive of good results, and most rapid in the chronic stage: here improvement sets in almost immediately after the first doses. At the commencement, so long as the acute stage is present, the quinine may be delayed for some days, if the danger be not pressing. On several occasions, Dr. Hamburger has seen the patient remain for several days in the same state, or even gradually beeome worse; the urine becoming darker and the exudations increased. But, when quinine was fearlessly given, a happy result followed. If marked improvement do not appear after the medicine has been given four or five days, it is to be omitted; but even in this instance it should not be regarded as being useless, as the specificity of the disease appears broken by it. The dose is gr. iss to gr. ij twice a day for children; and for adults gr. iij or gr. iv. During the use of the quinine, great attention must be paid to the diet; especial care being taken not to overload the irritable intestinal canal with slops._British Med. Jowrnal, May 18th, 1861, from Prag. Vierteljahrschrift, 1861.

21. Two Ounces of the Wine of the Seeds of Colchicum accidentally taken by a Gouty Subject with Relief.-Dr. JoskPH Bullar, Physician to the Royal South Hants Infirmary, records (Edinburgh Med. Journ., March, 1861) a remarkable case of this.

The subject of it was a gentleman, 34 years of age, whose father and grandfather were gouty, and he himself, from youth, had suffered severely from frequent attacks of gout. Feeling out of order, he had taken a blue pill on going to bed, and intended to take black draught the next moming; but his servant gave him instead two ounces of the wine of the seeds of colchicum. The mistake was not discovered until accidentally two hours had elapsed, when a physician was sent for, who considered it too late to use the stomach-pump, and expressed the belief that the overdose would work itself off by violent vomiting and purging, and advised that a dose of black dranglit should be at once taken, and another in an hour and a half. This was done, and the patient in the afternoon, while taking a drive, was taken with romiting, which continued incessantly for eight hours. The singular points in this case are, that there was no vomiting until seven hours after two ounces of colchicum wine were taken, and then violent yomiting for eight hours, with no ill effects except nervous weakness for the next day; but, on the contrary, with relief, for the last 24 years, of those severe and painful attacks of gont to which he had been subject for 10 years before.

\title{
SURGICAL PATHOLOGY AND THERAPEUTICS, AND OPERATTVE SURGERY.
}

22. Statistics of Amputation. G. F. Cooper and T. Holnes, Esq., give (Med. Times and Gaz., April 6,1861) the statistics of amputations performed in St. George's Hospital during seven years. The total number of amputations is 149 , and the mortality 41 or 27.6 per cent.

Therc were 76 amputations of the thigh, of which 25 , or 32.9 per cent., died; 40 of the leg, of which 13 , or 32.5 per cent., died; 22 of the arm, of which 3 , or 13.7 per eent., died; and 11 of the forearm, all of which recovered.

Amputations of the Thigh.-Of the 76 amputations of the thigh, 51 arc elassed as "pathologieal," of which 13 (25.6 per cent.) died, and 12 as "of expediency," of which 5 (41.6 per cent.) died. Putting these together, we should have 63 cases with a mortality of 18 or 28.5 per cent. The tranmatic amputations amount to 13 , of whieh 7 , of 53 per cent., died; of thesc 9 were primary, of whieh 5 died, and 4 secondary, of which 2 died.

Causes of Amputation and of Death.-Of the 51 cases classed as pathological, 8 were performed on account of abscess in the knee-joint; of these 5 died, one of sloughing of the stump and phthisis, and 4 of pyæmia. 35 were for chronic affections of the knee; of these 5 died -2 of pyæmia, as proved by 
post-mortem examinations; in 2 others, pyæmia was inferred from the symptoms during life; the fifth from phthisis, with sloughing of the stump.

The 8 remaining amputations were performed for various diseases: 2 for malignant disease, 2 for gangrene after ligature of the femoral artery, 2 for necrosis, 1 for arterial hemorrhage in phagedena, and 1 for necrosis and abscess after excision of the knee; of these 3 died, 1 of exhaustion, 1 of secondary hemorrhage, and one of pyæmia.

Of the 12 cases classed under the head of "amputations of expediency," 9 were on account of tumours, 2 of loss of skin after diffuse cellular inflammation, and 1 on account of old contraction of the knee with atrophy of the leg; of these 5 died-3 of pyrmia. 1 of exhaustion, and one of secondary hemorrhage.

Of the 13 traumatic amputations, 9 were primary, and 5 of these died-2 from pyæmia, 2 from shock, and 1 from other injury, viz., rupture of the bladdcr; this case should perhaps be omitted in estimating the mortality.

of the 4 secondary ampntations of the thigh, 2 died both of pyrmia.

So that of the 25 deaths after amputations of the thigh, we have as the causes:-

Pyæmia (in two cases only inferred from the symptoms during life) 16 Secondary hemorrhage

Phthisis

Exhaustion

Shock

Other injury .

Amputations of the Leg.-The total number of amputations of the leg is 40 , 31 being for disease, viz.-27 "pathological," and 4 "of expediency ;" and 9 traumatic, 6 primary, and 3 secondary.

Of the "pathological," almost all were performed on account of chronic disease of the bones of the foot and leg; those for acute disease of the anklejoint being only 3 in number, of which 1 died. Of the remaining 24,8 died4 from pyæmia, 1 from exhaustion, and 3 from the effects of strumous disease in remote parts of the body, the lungs, brain, and kidneys. Of the "amputations of expediency," 2 were performed on account of painful stumps of former amputations (in the samc limb), and 2 for tumours; all these recovered. Of the 9 traumatic amputations, 4 died-viz., 3 primary and 1 secondary-2 from pyæmia, 1 from secondary hemorrhage, and 1 from exhaustion.

Amputations of the Arm. The whole number of these amputations is 22 ; 14 for disease, of which 2 died, and 8 for accident, of which 1 died. Of the former class, 10 are put down as "pathological," all have bcen operated upon for disease of the bones or of the elbow-joint, where some contra-indication existed to excision. Of these 2 died, both of pyæmia. 4 are classed as operations "of expediency," 3 on account of the effects of burn, and 1 (at the shoulder-joint) for malignant tumour of the humcrus. All recovered. Of the traumatic amputations, 6 were primary and 2 secondary. 1 of the former died of pyæmia.

Amputations of the Forearm.-These are 11 in number, and all were successful. 6 were performed on account of disease of the hand, etc., 1 (" of expediency") for a tumour, and 4 were primary amputations.

Comparative Mortality of the V'arious Classes of Amputations.-Pathological amputations amount on the whole to 94 , of which 24 , or 25.5 per cent., died; amputations of expediency to 21 , of which 5 died, or 23.8 per cent. ; primary amputations to 25 , of which 9 , or 36 per cent., died; and secondary amputations to 9, of which 3, or 33.3 per cent., died. These figures, as far as they go, do not bear out Mr. Bryant's statement, that "amputations of expediency" are much more fatal than "pathological," and secondary than primary amputations. The list, however, is not sufficiently long to justify any very positive deductions.

Comparative Mortality of Circular and Flap Operations.-Of the 149 operations of which our table consists, 46 were flap amputations and 97 circular. of the remaining 6,3 were not noted as to this particular, and 3 cases of Syme's 
amputation are excluded. The results were as follows: of 74 amputations of the thigh, 52 were circular, 15 of which died, showing a mortality of 28.8 per cent.; 22 were flap, and 10 died, showing a mortality of 45.4 per cent.

The shortest period between the operation and the patient's discharge from the hospital was, in the circular, 23 days, and in the flap 24 days; the longest in the circular, 126 , and in the flap 105 days; the average period of cure in the circular 60 , and in the flap 42 days.

Of 37 amputations of the leg, 21 were circular, of which 3 died, a mortality of 14.2 per cent.; 16 werc flap, and 8 died, a mortality of 50 per eent. With respect to the period of their stay in the hospital, the shortest period was in the eircular operations 19, and in the flap 20 days; the longest, in the cireular 120 , and in the flap 94 days; the average, in the former 49 , and in the latter 46 days.

It ought to be noted that, in estimating these flaps for the flap operations, the details of one case are excluded, in consequence of its exceptional character. It was that of a man who submitted to amputation of the leg twice, on account of irritable and painful stump. 'The foot had originally been removed by Syme's amputation at another hospital, and the leg was twice aniputated at St. George's. On each occasion he was kept in the house a long while, on account of the painful and irritable condition of the integuments. It appeared unfair to represent the delay which this unusual state of parts occasioned as a result of the mode of amputating.

Of 22 amputations of the arm, 17 were circular, of which 2 died, a mortality of 11.8 per cent.; 5 were flap, of which 1 died, a mortality of 20 per cent. The shortest period in hospital was, in the former, 20, in the latter, 26 days; the longest, in the former, 96 , in the latter, 70 days; the average of the former, 41 , of the latter, 51 days.

of 10 amputations of the forearm, 7 were circular and 3 flap; none died. The shortest time in the hospital was, in the former class, 20, in the latter, 17 days ; the longest, in the former, 142 , in the latter, 50 ; the average of the former, 44 , of the latter, 29 days.

This shows that out of 97 circular amputations of all kinds, 20 died, a mortality of $20.6 \mathrm{per}$ cent.; while out of 41 flap, 19 died, a mortality of 41.3 per cent., or just double that of the circular, and that this excess of the mortality of the flap over the circular prevailed in all classes of amputations. More extensive data are required, however, to prove beyond question that this excess is constant, and, if so, clinical observation must be called in to show the cause upon which it depends. It may be conjectured that sloughing of the flaps would be a frequent cause of death after the flap operation; but our data do not entirely bear out this idea, nor are we prepared, at present to point out any decided difference in the canses of death after the two kinds of amputation. The list of flap amputations comprises 8 in which the flaps were formed after Mr. 'Teale's method-by the rectangular incision. In several of these cases the long flap sloughed, and 3 out of the 8 cases proved fatal. It should, however, in justice to the respected author of this operation, be remarked that some of these patients were in bad health at the time of operation. The flap operation appears (especially in the thigh) to have some advantage in respect of rapidity of cure.

Influence of Sex.-Of the 149 patients comprised in these tables, 118 were males, and 31 females. The mortality was 34 , or 28.8 per cent., of the former, and 7 , or 21.9 per cent., of the latter. If we remember that males are far more frequently the subjects of traumatic amputations, and that these are far more fatal than operations for disease, we shall come to the conclusion, probably, that females bear the operation worse than males. Of the whole number (34) of traumatic amputations, only 2 were performed on females.

Influence of Age.-For the purpose of estimating the influence which age cxerts on the mortality, the cases may be divided into four groups: those oceurring in childhood, or below the age of 15 ; in youth, or from 15 to 25 years of age; in adults, between 25 and 60 ; and in advanced life, beyond the age of 60 .

In children, below the age of 15 , we find 18 operations, of which 2 died; but as one of these was the result of other and necessarily fatal injuries, it would

No. LXXXIII.-JUnY 1861. 
be more correct to exelude this case, and say that of 17 operations, 1 died of pyæmia.

In youth, 45 operations are reeorded, of whieh 6 died, or 13.3 per eent.

In adult age, 80,31 of which died, or 38.7 per cent.

In old age, 6,2 of whieh died, or 33.3 per cent.

Thus we see that in ehildren amputation is ordinarily successful; the only death recorded, excluding the ease above referred to, was in a strumous boy on the limits of the prescribed age, with abscess in the knee-joint. In youth the proportion of deaths is far less than in adult age. In old age, there is no reason to eonelude that the patients, cateris paribus, bear the operation worse than adults, but our figures are too small to draw any conclusions.

The Causes of Death.-The total number of deaths was 41. The assigned eauses of death are as follows:-

\begin{tabular}{|c|c|c|c|c|}
\hline Pyæmia . . . . . & in 24 & cases, & or 58.5 & er eent \\
\hline Exhaustion (without hemorrhage) & & & or 17 & \\
\hline Exhaustion with secondary hemorrhage & in 4 & “ & or 9.7 & " \\
\hline Viseeral disease $\quad . \quad . \quad$. & in & " & 9.7 & " \\
\hline Diffuse inflammation and gangrene & in & “ & 2.4 & " \\
\hline Other injuries . & in 1 & “ & 2.4 & " \\
\hline
\end{tabular}

In 9 eases no post-mortem examination was made; of these the eauses assigned from the symptoms during life, were-pyamia in 5 cases, exhaustion in 3 , and secondary hemorrhage in 1 .

Thus, it will be seen that in our experience, pyæmia oeeupies a much larger space as a eause of death, than in Mr. Bryant's table: while exllaustion (without secondary hemorrhage) is proportionately diminished, appearing as 17 per cent. only, while in the Guy's Hospital records it stands for 33 per cent. of the fatal eases. In Mr. Bryant's paper, no mention is made of the authority on which his statements rest; whether all or what proportion were examined after death, whether the cases produced inelude all the operations during a certain period, and if so, what period, with other interesting partienlars. Thus, in this instance, it would require very strong evidence to eonvinee us that one out of every three fatal cases of well-selected amputations died of mere exhaustion.

If we separate the amputations, on Mr. Bryant's plan, into " pathological," "amputations of expedieney," "primary," and "secondary," we find the causes of death in each elass as follows :-

Of 94 "pathological ampntations," 24 died, the eauses of death being-

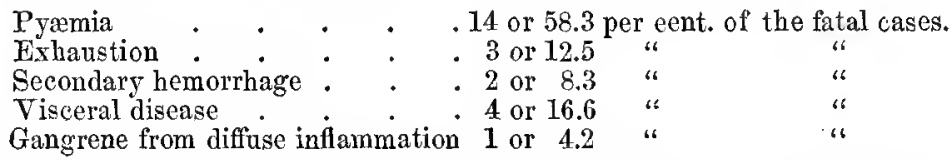

Of 21 "amputations of expediency," 5 died-3 of pyæmia, or 60 per cent.; 1 of exhaustion, or 20 per eent.; and 1 of secondary hemorrhage, or 20 per cent. of the fatal cases.

Of 25 primary amputations, 9 died -5 of pyacmia, 55.5 per eent.; 1 of secondary hemorrhage, or 11.1 per eent.; 2 of shock, or 22.2 per cent; ; and 1 of other injuries, or 11.1 per ecnt.

Of 9 secondary amputations, 3 died-2 of pyæmia, or 66.6 per eent.; and 1 of exhaustion, or 33.3 per cent.

23. Excision of the Tendons in Amputation of the Forearm at the Lower Third.-Mr. HugH Croskerx eommunieated to the Surgieal Society of Treland (April 13, 1861) the following interesting observations on this subject.

The thousand dangers that have, in times past, been mentioned as being likely to occur after flap amputations at the lower third of the forearm, still continue to influence many surgeons of eminenee to discard this operation altogether; and many limbs are now removed near the elbow, where a useful member might have been saved. This subject is still, unhappily, a matter of eontroversy, and the probability of the occnrrenee of the untoward results 